\title{
ANTIMICROBIAL EVALUATION OF MALEIMIDE MONOMERS, HOMOPOLYMERS AND COPOLYMERS CONTAINING AZO, SULFONAMIDE AND THIAZOLE GROUPS
}

\author{
Shivira bapna ${ }^{a}$, B.L.Hiran ${ }^{b}$, Sapna Jain ${ }^{\mathrm{C}}$ \\ aDepartment of Chemistry, Geetanjali Institute of Technical studies, Udaipur \\ Email: drshivirabapna@gmail.com \\ bUniversity College of Science, Mohanlal Sukhadia University, Udaipur \\ 'Department of Chemistry, Guru Nanak Girls PG college, Udaipur
}

\begin{abstract}
New maleimide Monomers, homopolymers and copolymers containing azo, sulfonamide and thiazole groups were synthesized. The structures of newly synthesized compounds have been characterized on the basis of their spectroscopic data (FT-IR and ${ }^{1} \mathrm{H}-\mathrm{NMR}$ ). Antimicrobial studies of synthesized compounds were performed using agar well diffusion method. All the compounds showed pronounced activity against bacterial strains in comparison to activity against fungal strains. The highest antibacterial potency was exhibited by the homopolymer HPSPMI against Escherichia coli, Klebsiella pneumoniae and Bacillus subtilis. The activity of HPSPMI against later two was more pronounced than the standard drug used. Only Selected compounds showed antifungal activity. Appreciable results were found against Aspergillus fumigates but not with Candida albicans. HPSPMI showed highest activity against Aspergillus fumigates. Surprisingly after homo and copolymerization, maximum compounds exhibited not only pronounced antibacterial activity but also antifungal activity.
\end{abstract}

\section{Keywords}

maleimide monomers; homopolymers and copolymers; containing azo; sulfonamide and thiazole groups; antimicrobial activity

\section{Academic Discipline And Sub-Disciplines}

Chemistry and Polymer chemistry

\section{TYPE (METHOD/APPROACH)}

Synthesis of Monomers \& polymers and antimicrobial assay

\section{Council for Innovative Research}

Peer Review Research Publishing System

\section{Journal: Journal of Advances in Chemistry}

\author{
Vol. 11, No. 1 \\ editorjaconline@gmail.com




\section{INTRODUCTION}

Antimicrobial polymer, also known as polymeric biocides is a class of polymers with antimicrobial activity or the ability to inhibit the growth of microorganisms. Significant advance in the past three decade have been made in the synthesis and application ${ }^{[1]}$ of polymers to prevent microbial attack ${ }^{[2][3][4][5]}$ and degradation for diverse end uses. This led to the discovery of a variety of new polymers with bioactive functional groups. Antimicrobial polymer coatings are intended for modification of packaging materials to inhibit spoilage of foodstuffs (bakery, confectionery, dairy, meat, fruit and vegetables), for which they are filled with antimicrobial components. Antimicrobial packages have been developed, Antimicrobial $[6][7][8][9][10][11]$ polymers are ideal for applications in hand-held water filters, surface coatings and fibrous disinfectants because they can be fabricated by various techniques and can be made insoluble in water. The design of insoluble polymers that can inactive, kill or remove target microorganisms by mere contact without releasing any reactive agents to the bulk phase being disinfected is desired. Applications of antimicrobial polymers are also going to exploit in textile industries. Antifungal agents (such as ketoconazole) are often found in anti-dandruff shampoos. The field of antimicrobial polymers ${ }^{[12]^{13}[14][15]}$ has progressed steadily but slowly over the past years it appears to be on the verge of rapid expansion. The greater need for materials that fight infection will give encouragement for discovery and use of antimicrobial polymers. The use of antimicrobial polymers ${ }^{[16][17][18][19][20]}$ offers promise for enhancing the efficacy of some existing antimicrobial agents and minimizing the environmental problems accompanying conventional antimicrobial agents by reducing the residual toxicity of the agents, increasing their efficiency and selectivity and prolonging the lifetime of the antimicrobial agents. Research concerning the development of antimicrobial polymers represents a great challenge for both the academic world and industry. In this article polyimides are chosen as the polymeric substrate to describe antimicrobial properties.

\section{EXPERIMENTAL}

\section{Procedure: Monomer Synthesis}

Novel monomers N-[4-(Azophenyl) phenyl] maleimide monomer (PAPMI), N-[4-(Sulfonamide) phenyl] maleimide monomer (PSPMI), N-[4-(Phenyl) thiazole] maleimide monomer* (PTHPMI) were synthesized using a general procedure which has been described below (Sheme-1).

\section{Step - I}

The solution of maleic anhydride $(0.1 \mathrm{~mol})$ in DMF was gradually added over a period of $10-15 \mathrm{~min}$. to a solution of parent compound (from which monomer has to be synthesized) in appropriate quantity of DMF solvent. The solution was stirred for 6-7 hrs at room temperature.

\section{Step - II}

It was again stirred for 6-7 hrs with 5 to $8 \mathrm{gm} \mathrm{P}_{2} \mathrm{O}_{5}$ and 4 to 6 drops of concentrated $\mathrm{H}_{2} \mathrm{SO}_{4}$ at 65 to $80^{\circ} \mathrm{C}$ temperature. The resulting solution was poured into crushed ice or cold water to precipitate monomer. The solution was filtered and washed with distilled water, sodium bicarbonate and again with distilled water. The remaining residue left behind was of crude monomer, which was filtered and dried in vacuum. On drying, crude monomer was crystallized with appropriate solvent to obtain pure monomer. The monomer synthesis was confirmed by FT-IR, ${ }^{1} \mathrm{H}-\mathrm{NMR}$ and elemental analysis.

"Before the synthesis of PTHPMI, it's parent compound 2-amino-4-phenyl thiazol was synthesized using following method: A mixture of 0.1 mole acetophenone, 0.1 mole iodine and 0.2 mole thiourea was heated on water both for 4-5 hrs. The resultant mixture was cooled and triturated with 100 c.c. diethyl ether. It was filtered and washed twice with 50 c.c. diethyl. It was filtered and washed twice with 50 c.c. diethyl ether and dried. After completely drying it was dissolved in hot water and immediate treated with concentrated $\mathrm{NH} 4 \mathrm{OH}$ until the solution become alkaline. As the solution became alkaline we got precipitation. It was filtered and washed 3 to 4 times with cold water and dried.
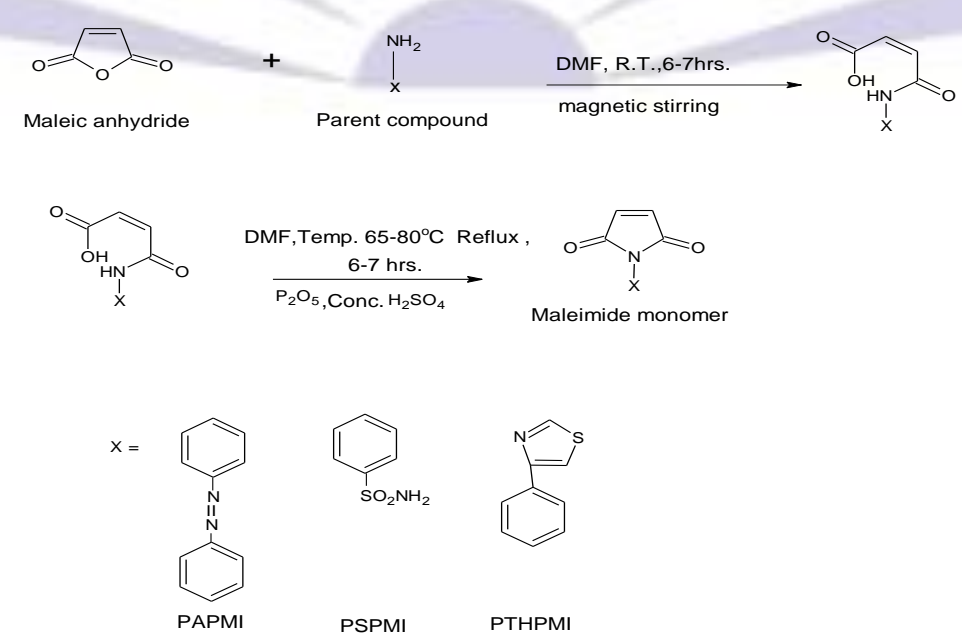

Scheme-1 


\section{Procedure: Homopolymer Synthesis}

These monomers were further used to synthesize homopolymers Poly- $\mathrm{N}-[4-($ Azophenyl) phenyl] maleimide (HPAPMI), Poly-N-[4-(Sulfonamide) phenyl] maleimide (HPSPMI), Poly-N-[4-(Phenyl) thiazole] maleimide (HPTHPMI) via free radical polymerization using AIBN as initiator. A general procedure was used for homopolymerization, which has been described below (Scheme-2).

0.01 mole of monomer was taken in 40 to $50 \mathrm{ml}$ DMF with $150 \mathrm{mg}$ AIBN in a two necked round bottom flask and reflux at 80 to $85^{\circ} \mathrm{C}$ for $48 \mathrm{hrs}$. After polymerization for a given time, the reaction mixture was poured into $10 \%$ methanol water mixture to precipitate homopolymer. Homopolymer was filtered, purified by crystallization using appropriate solvent and dried under vacuum. Homopolymer synthesis was confirmed by FT-IR and ${ }^{1} \mathrm{H}-\mathrm{NMR}$.<smiles>[Y]N1C(=O)C=CC1=O</smiles><smiles>[X]N1C(=O)C2C3CC(C)C(C3)C2C1=O</smiles>

Homopolymer

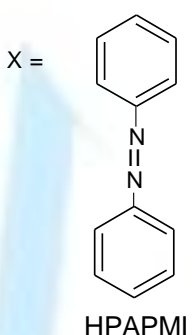<smiles>CCCPC(=O)c1ccccc1</smiles>

Scheme-2

\section{Procedure: Copolymer Synthesis}

Above mentioned monomer units were used to synthesize following copolymers;

Poly(N-[4-(Azophenyl) phenyl] maleimide-co-N-[4-(Sulfonamide) phenyl] maleimide); PAPSPMI Poly(N-[4-(Azophenyl) phenyl] maleimide-co-N-[4-(Phenyl) thiazole] maleimide); PATHPMI

Poly(N-[4-(Azophenyl) phenyl] maleimide-co-N-[4-(Phenyl) thiazole] maleimide-co-N-[4-(Sulfonamide) phenyl] maleimide); PATHSPMI

A general procedure was used to synthesize all copolymers, which has been described below $($ Scheme-3,4).

Monomer units were taken in equimolar quantity ( 0.01 mole) with $40-60 \mathrm{ml}$ DMF solvent into a three necked round bottom flask. Compound should be dissolved completely. In the reaction solution $150 \mathrm{mg}$ AlBN was introduced and shaked well to dissolve AIBN completely. Now the reaction mixture was refluxed at $80^{\circ} \mathrm{C}$ for $48 \mathrm{hrs}$. The reaction mixture was poured into $10 \%$ methanol water mixture to precipitate copolymer after polymerization for a given time. Copolymer was filtered, washed twice or thrice with distilled water and dried completely under vacuum. Crude copolymer was crystallized using appropriate solvent to get purity of sample. Synthesis of copolymer was confirmed by ${ }^{1} \mathrm{H}-\mathrm{NMR}$ and FTIR spectral analysis.<smiles>O=C1C=CC(=O)N1c1nc(-c2ccccc2)cs1</smiles>

PTHPMI<smiles>NS(=O)(=O)c1ccc(N2C(=O)C=CC2=O)cc1</smiles>

PSPMI

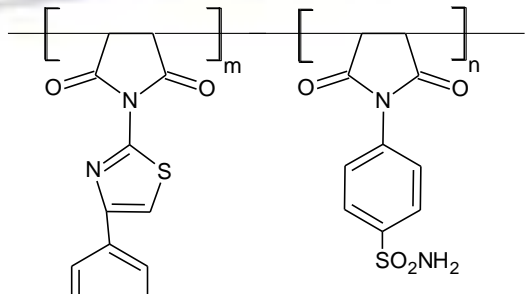

PTHSPMI 
<smiles>O=C1C=CC(=O)N1c1ccc(N=Nc2ccccc2)cc1</smiles>

PAPMI

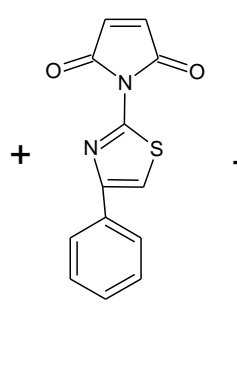

PTHPMI

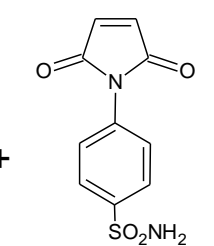

PSPMI
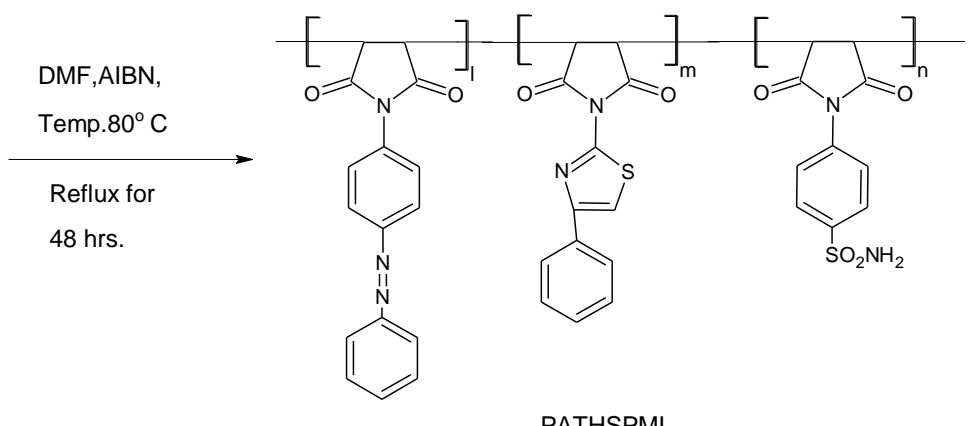

PATHSPMI

Scheme-3,4

\section{SPECTRAL ANALYSIS}

FTIR spectra of synthesized compounds were recorded on Perkin-Elmer Spectra RXI $\left(4000-450 \mathrm{~cm}^{-1}\right)$ FTIR spectrophotometer using $\mathrm{KBr}$ pellet technique. ${ }^{1} \mathrm{H}-\mathrm{NMR}$ spectra of samples were recorded on a Bruker DPX-300 spectrometer at $300 \mathrm{MH}_{z}$ with acetone as a solvent.

PAPMI \& PSPMI: As reported in Int. J. of Chemistry and Chemical Engineering ${ }^{[21]}$

2-amino-4-phenyl thiazol: light yellow, $75 \%$ Yield, $\mathrm{mp}: 144-146^{\circ} \mathrm{C} ; \mathbf{F T I R}\left(\mathbf{C M}^{-1}\right)$ : $\mathrm{Ar} . \mathrm{C}=\mathrm{C}$ and $\mathrm{C}=\mathrm{N} 1604.1,1522.1$, 1439.5, 1334.4 , Ar. C-H str., 3020.1, phenyl ring 762.2, 669.2, C-S str. $611.7, \mathrm{NH}_{2}$ sym. and asym. Str. 3247.0 and 3392; ${ }^{1} \mathrm{H}-\mathrm{NMR}\left(300 \mathrm{MHz}_{\mathrm{z}}\right.$,acetone, $\left.\delta \mathrm{ppm}\right): 4.85\left(\mathrm{~s}, 2 \mathrm{H}, \mathrm{NH}_{2}\right), 7.42(\mathrm{~s}, 1 \mathrm{H}$, thiazole), $7.48-8.18$ (m, 5H, phenyl), Figure $1 \& 1.1$

PTHPMI:_Dark green, $83 \%$ Yield, mp:162-163 ${ }^{\circ} \mathrm{C}$; FTIR(CM $\left.{ }^{-1}\right): \mathrm{C}=\mathrm{C}$ Str. 1618.2, =C-H Str. 3098.2, C = O Sym. and asym. str. 1716.9 \& 1782.2, Ar. C=C str. 1520.2, Ar. C-H str. 3021.3, Ar. C-N str. 1304.3, phenyl ring 671.1, 765.1, C-S Str. 627.0; ${ }^{1} \mathrm{H}-\mathrm{NMR}\left(300 \mathrm{MH}_{\mathrm{z}}\right.$, acetone , $\left.\delta \mathrm{ppm}\right): 7.59(\mathrm{~s}, 2 \mathrm{H}, \mathrm{HC}=\mathrm{CH}), 7.21(\mathrm{~s}, 1 \mathrm{H}$, thiazole), $7.32-7.96(\mathrm{~m}, 5 \mathrm{H}$, phenyl), Figure 2 \& 2.1

HPAPMI: Dark reddish brown, $85 \%$ Yield, FTIR(CM $\left.{ }^{-1}\right)$ : C-C Str. 2951.2, - C-H Str. 1450.0, C = O Sym. and asym. 1714.2, 1780.0, Ar. C=C str. 1504.1, 1599.4, Ar. C-H str. 3019.4, Ar. C-N str.1302.2, phenyl ring 842.7, 688.1, 769.7; ${ }^{1} \mathrm{H}-$ NMR (300 MHz ,acetone, $\delta \mathrm{ppm}): 3.04(\mathrm{~s}, 2 \mathrm{H}, \mathrm{HC}-\mathrm{CH}), 7.44-8.02(\mathrm{~m}, 9 \mathrm{H}$, phenyl), Figure $3 \& 3.1$

HPSPMI: Black, $67 \%$ Yield, FTIR(CM $\left.{ }^{-1}\right)$ : C-C Str. 2972.7, - C-H Str. 1425.0, C = O Sym. and asym. 1713.2, 1778.5, Ar. $\mathrm{C}=\mathrm{C}$ str. 1518.9, 1603.9, Ar. C-H str. 3020.1, Ar. C-N str., 1365.3, phenyl ring 797.7, S = O Str. 1027.5, SO 2 Sym. and asym. 1137.5, 1260.1. $\mathrm{NH}_{2}$ Sym. and asym. 3250.3, 3342.7, C - S Str. 672.7; ${ }^{1} \mathrm{H}-\mathrm{NMR}\left(300 \mathrm{MHz}_{\mathrm{z}}\right.$,acetone, $\left.\delta \mathrm{ppm}\right): 3.12$ $(\mathrm{s}, 2 \mathrm{H}, \mathrm{HC}-\mathrm{CH}), 6.62\left(\mathrm{~s}, 2 \mathrm{H}, \mathrm{NH}_{2}\right), 6.74-7.28$ (dublets, $4 \mathrm{H}$, phenyl) Figure 4 \& 4.1

HPTHPMI: Dark green ,72 \% Yield, FTIR(CM $\left.{ }^{-1}\right)$ : C-C Str. 2962.8, - C-H Str. 1445.9, C = O Sym. and asym. 1725.8, 1776.2, Ar. C=C str. 1546.4, Ar. C-H str. 3020.0, Ar. C-N str. 1344.2, phenyl ring 670.2, 768.6, C-S Str. of thiazole ring (very weak) 631.2; ${ }^{1} \mathrm{H}-\mathrm{NMR}\left(300 \mathrm{MHz}_{\mathrm{z}}\right.$,acetone, $\left.\delta \mathrm{ppm}\right): 2.94(\mathrm{~s}, 2 \mathrm{H}, \mathrm{HC}-\mathrm{CH}), 7.32-8.05(\mathrm{~m}, 5 \mathrm{H}$, phenyl) Figure 5 \& 5.1

PAPSPMI: As reported in Int. J. of Chemistry and Chemical Engineering ${ }^{[21]}$

PTHSPMI: Dark Greenish black, $86 \%$ Yield, FTIR(CM $\left.{ }^{-1}\right)$ : C-C Str. 2958.8, - C-H Str. of maleimide ring

1444.2, C = O Sym. and asym. Str. 1715.4, 1779.2, Ar. C=C str. 1506.0, 1593.1, Ar. C-H str. 3022.0, Ar. C-N str. 1334.3 phenyl ring 671.1, 764.3, $\mathrm{S}=\mathrm{O}$ Str. 1023.6, $\mathrm{SO}_{2}$ Sym. and asym. 1116.5, 1383.7, $\mathrm{NH}_{2} \mathrm{Sym}$. and asym. 3233.9, 3298.2, C - S Str. 621.1, ${ }^{1} \mathrm{H}-\mathrm{NMR}\left(300 \mathrm{MHz}_{\mathrm{z}}\right.$, acetone and $\left.\mathrm{CDCl}_{3}, \delta \mathrm{ppm}\right): 2.95(2 \mathrm{H}, \mathrm{HC}-\mathrm{CH}), 7.19(\mathrm{~s}, 1 \mathrm{H}$, thiazole $), 6.67(\mathrm{~s}, 2 \mathrm{H}$, $\mathrm{NH}_{2}$ ), $7.02-8.00$ (m, $9 \mathrm{H}$,phenyl), Figure 6 \& 6.1

PATHSPMI: Greenish black, $62 \%$ Yield , FTIR(CM $\left.{ }^{-1}\right)$ : C-C Str. 2968.1, C - H Str. 1480.1, C=O Sym. and asym. 1718.8, 1776.1, Ar. C=C str. 1591.3, Ar. C=H str. 3021.0, Ar. C-N str. 1363.2, phenyl ring 673.1, 767.4, S=O Str. $1027.8, \mathrm{SO}_{2}$ Sym. and asym. Str. 1158.2, 1319.3, $\mathrm{NH}_{2}$ Sym. and asym. 3353.7, 3288.5, C - S Str. 620.4, ${ }^{1} \mathrm{H}-\mathrm{NMR}\left(300 \mathrm{MHz}_{\mathrm{Z}}\right.$, acetone, $\delta \mathrm{ppm}): 3.09(2 \mathrm{H}, \mathrm{HC}-\mathrm{CH}), 6.64\left(\mathrm{~s}, 2 \mathrm{H}, \mathrm{NH}_{2}\right), 7.38(\mathrm{~s}, 1 \mathrm{H}$, thiazole), $6.76-8.01(\mathrm{~m}, 18 \mathrm{H}$, phenyl), Figure 7 \& 7.1

\section{ANTIMICROBIAL STUDY}

Antimicrobial activity of bioactive compounds against test microorganisms (bacteria and fungi) was evaluated using Agar Well Diffusion Assay (Lehrar et al., 1991; Reddish 1929). The agar well diffusion assay was carried out by preparation of 4 to 6 wells of $10 \mathrm{~mm}$ diameter using a sterile cork borer per $90 \mathrm{~mm}$ agar plate aseptically (nutrient agar and sabouraud dextrose agar were used for antibacterial and antifungal activity respetively). A known quantity (10 $\mu$ l) of microorganism was grown on agar plates. The agar cylinders were removed using a sterile loop. The wells were grouped as the test well and the control or standard well. The test wells were filled with $200 \mu \mathrm{l}$ solution of sample compounds at $500 \mu \mathrm{g} / \mathrm{ml}$ concentration and the control well was filled with the same concentration and same volume of the standard. The wells were then sealed with agar and kept for 10 minutes. The plates were incubated at room temperature for 24 hours for antibacterial and 3 days for antifungal susceptibility. After incubation a zone referred to zone of inhibition developed around the well if the sample is sensitive towards the microorganism species. The inhibition zones were recorded in 
millimeters $(\mathrm{mm})$ in the test well as the control well. An organism, which was placed on the agar, will not grow in the area around the well or in the zone of inhibition if it is susceptible to the sample compound.

\section{Antibacterial Assay}

Antibacterial susceptibility of above following compounds was tested by agar well diffusion assay using following microorganisms: Escherichia coli, Klebsiella pneumoniae, Pseudomonas aeruginosa and Bacillus subtilis (Figure a\&b). To perform antibacterial susceptibility, ciprofloxacin was used as standard or control to reveal the potency of synthesized compound. It is a synthetic chemotherapeutic antibiotic of the fluoroquinolone drug class. It is a secondgeneration fluoroquinolone antibacterial. It kills bacteria by interfering with the enzymes that cause DNA to rewind after being copied, which stops synthesis of DNA and of protein.

Table 1: Antibacterial Assay of Synthesized Compounds

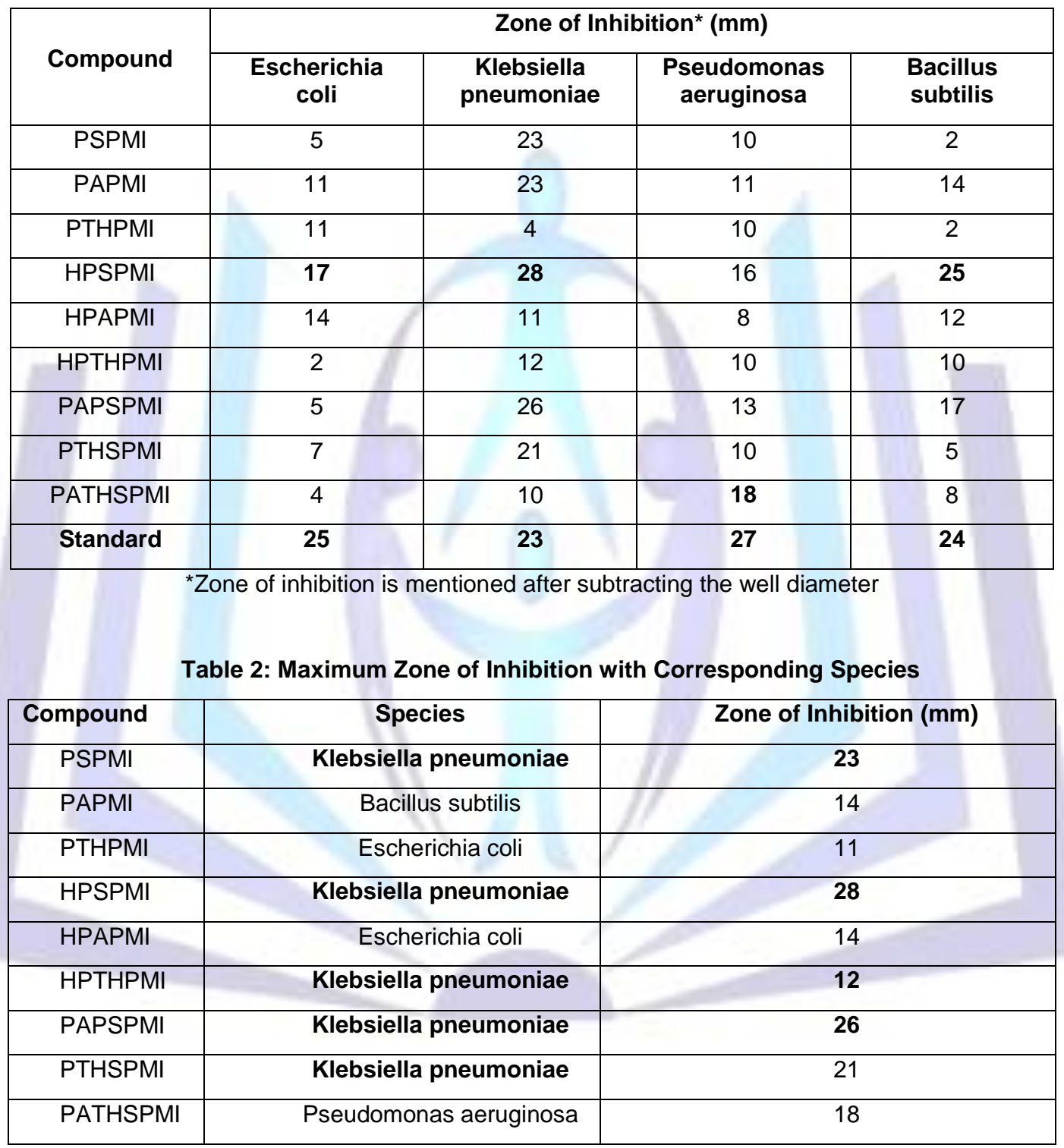


Table 3: Comparative Antibacterial Assay of Monomers, Corresponding Homopolymers and Copolymers

\begin{tabular}{|c|c|c|c|c|c|}
\hline & & & Zone of & ition (mm) & \\
\hline & ound & Escherichia & Klebsiella & Pseudomonas & Bacillus \\
\hline$M$ & PSPMI & 5 & 23 & 10 & 2 \\
\hline $\mathrm{H}$ & HPSPMI & 17 & 28 & 16 & 25 \\
\hline$M$ & PAPMI & 11 & 23 & 11 & 14 \\
\hline $\mathrm{H}$ & HPAPMI & 14 & 11 & 8 & 12 \\
\hline $\mathrm{C}$ & PAPSPMI & 5 & 26 & 13 & 17 \\
\hline$M$ & PTHPMI & 11 & 4 & 10 & 2 \\
\hline $\mathrm{H}$ & HPTHPMI & 2 & 12 & 10 & 10 \\
\hline C & PTHSPMI & 7 & 21 & 10 & 5 \\
\hline
\end{tabular}

Here $\mathrm{M}=$ Monomer, $\mathrm{H}=$ Homopolymer, $\mathrm{C}=$ Copolymer

\section{Antifungal Assay}

Antifungal susceptibility of PSPMI, PAPMI, PTHPMI, HPSPMI, HPAPMI, HPTHPMI, PAPSPMI, PTHSPMI and PATHSPMI was performed using agar well diffusion assay using Aspergillus fumigatus and Candida albicans (Figure $b$ ).

To screen antifungal susceptibility of compounds, fluconazole was used as standard or control to expose the potency of the synthesized compounds. It is a triazole antifungal drug used in the treatment and prevention of superficial and systemic fungal infections.

Table 4: Antifungal Assay of Synthesized Compounds

\begin{tabular}{|c|c|c|}
\hline \multirow{2}{*}{ Compound } & \multicolumn{2}{|c|}{ Zone of Inhibition* $(\mathbf{m m})$} \\
\cline { 2 - 3 } & Aspergillus fumigatus & Candida albicans \\
\hline PSPMI & 0 & $\mathbf{1}$ \\
\hline PAPMI & 0 & $\mathbf{1}$ \\
\hline PTHPMI & 0 & 0 \\
\hline HPSPMI & $\mathbf{1 6}$ & 0 \\
\hline HPAPMI & 13 & $\mathbf{1}$ \\
\hline HPTHPMI & 0 & 0 \\
\hline PAPSPMI & 15 & 0 \\
\hline PTHSPMI & 6 & 0 \\
\hline PATHSPMI & 0 & $\mathbf{1 4}$ \\
\hline Standard & $\mathbf{0}$ & dimeter \\
\hline
\end{tabular}

* Zone of inhibition is mentioned after subtracting the well diameter 
Table 5: Comparative Antifungal Assay of Monomers, Corresponding Homopolymers and Copolymers

\begin{tabular}{|c|c|c|c|}
\hline \multirow{2}{*}{\multicolumn{2}{|c|}{ Compound }} & \multicolumn{2}{|c|}{ Zone of Inhibition (mm) } \\
\hline & & Aspergillus fumigatus & Candida albicans \\
\hline $\mathrm{M}$ & PSPMI & 0 & 1 \\
\hline $\mathrm{H}$ & HPSPMI & 16 & 0 \\
\hline M & PAPMI & 0 & 0 \\
\hline $\mathrm{H}$ & HPAPMI & 13 & 0 \\
\hline C & PAPSPMI & 15 & 0 \\
\hline M & PTHPMI & 0 & 1 \\
\hline $\mathrm{H}$ & HPTHPMI & 0 & 1 \\
\hline $\mathrm{C}$ & PTHSPMI & 6 & 0 \\
\hline
\end{tabular}

In the antibacterial and antifungal studies symbols 1 to 10 were used for the compounds and standard. Their details are:

\begin{tabular}{|c|l|c|l|}
\hline Symbol & Compound & Symbol & Compound \\
\hline 1 & PTHSPMI & 6 & PAPMI \\
\hline 2 & PAPSPMI & 7 & HPTHPMI \\
\hline 3 & HPSPMI & 8 & PTHPMI \\
\hline 4 & HPAPMI & 9 & PSPMI \\
\hline 5 & PATHSPMI & 10 & Standard \\
\hline
\end{tabular}

\section{RESULT AND DISCUSSION}

$\mathrm{N}$-substituted maleimide monomers, homopolymers and copolymers were synthesized. Terpolymer synthesis was also carried out to find out the possibility of terpolymer formation. Antimicrobial study was done with all synthesized compounds.

Antibacterial assay- Table 1 shows that all the tested compounds performed moderate to excellent antibacterial activity against the bacterial strains. It is evident from this table that the highest antibacterial activity was exhibited by the homopolymer HPSPMI against Escherichia coli, Klebsiella pneumoniae and Bacillus subtilis. Surprisingly the activity of HPSPMI against Klebsiella pneumoniae and Bacillus subtilis was more pronounced than the standard drug used. The zone of inhibition was found higher for HPSPMI than standard against above species. This reveals higher potency of synthesized compounds towards antibacterial activity.

The data presented in table 2 indicates the maximum zone of inhibition for each compound with corresponding species. The results showed that the maximum zone of inhibition or highest antibacterial activity was exhibited against Klebsiella pneumoniae. Escherichia coli was next in these results.

Table 3 includes comparable data of monomers with their corresponding homopolymers and copolymers.

PSPMI and HPSPMI: It is evident from the table that after homopolymerization of PSPMI, the potency of HPSPMI towards antibacterial activity increased to great extent against all species.

PTHPMI, HPTHPMI and PTHSPMI: The effect of all these three on different species was not uniform except pseudomonas aeruginosa, all three gave the same spectrum with zone of inhibition $10 \mathrm{~mm}$. PTHPMl was found the most effective against Escherichia coli. In case of Klebsiella pneumoniae PTHSPMI was the best and HPTHPMI was found the most effective against Bacillus subtilis.

Antifungal Assay - The data mentioned in table 4 indicates that compounds did not perform the antifungal potency as they performed against bacterial species. Surprisingly only few of them showed antifungal activity against selected fungi. The highest antifungal activity against Aspergillus fumigatus was exhibited by HPSPMI. The result of PAPSPMI was also

very appreciable and comparable to HPSPMI. The most wondering fact that can be observed from the table was all compounds that exhibited antifungal activity against Aspergillus fumigatus were more pronounced than standard drug fluconazole. PSPMI, PAPMI, PTHPMI, HPTHPMI and PATHSPMI did not show antifungal activity against Aspergillus fumigates.

The results against Candida albicans were shocking and contrary of the former discussed. The compounds that did not exhibit activity against Aspergillus fumigatus, most of them showed activity against Candida albicans and vice versa. 
PSPMI, PTHPMI and HPTHPMI showed very moderate antifungal activity against Candida albicans. In comparison to standard drug, the results were very poor.

Table 5 includes comparable data of monomers with their corresponding homopolymers and copolymers.

PSPMI and HPSPMI: Antifungal potency of homopolyer HPSPMI was pronounced over PSPMI against Aspergillus fumigatus. In case of Candida albicans contrary results were observed. HPSPMI did not exhibit antifungal activity whereas PSPMI gave moderate results.

PTHPMI, HPTHPMI and PTHSPMI: No antifungal activity was exhibited by monomer PTHPMI and its homopolymer HPTHPMI against Aspergillus fumigatus, only copolymer PTHSPMI exhibited antifungal potency. In case of Candida albicans just contrary results were found. PTHPMI and HPTHPMI showed moderate antifungal activity, however PTHSPMI did not exhibit such kind of activity.

\section{CONCLUSION}

All synthesized compounds showed excellent to moderate antimicrobial potency. The highest antibacterial and antifungal activity was exhibited by the homopolymer HPSPMI against Escherichia coli, Klebsiella pneumoniae and Bacillus subtilis (bacterial species) and Aspergillus fumigates (fungal species). It again proves antimicrobial potency of sulfonamide group. The activity of HPSPMI against Klebsiella pneumoniae and Bacillus subtilis was more pronounced than the standard drug Ciprofloxacin. After homo and copolymerization, maximum compounds showed pronounced antibacterial as well as antifungal activity.

Synthesized compounds showing antimicrobial activity may be beneficial in numerous diseases where standard

Ciprofloxacin \& Fluconazole is used like typhoid fever, urinary tract, lower respiratory tract infections, acute sinusits, infectious diarrhea, bone and joint infections, skin and skin structure infections onychomycosis, candidiasis, Tinea corporis, Histoplasmosis etc. These results signify that the compounds are useful for antimicrobial applications.
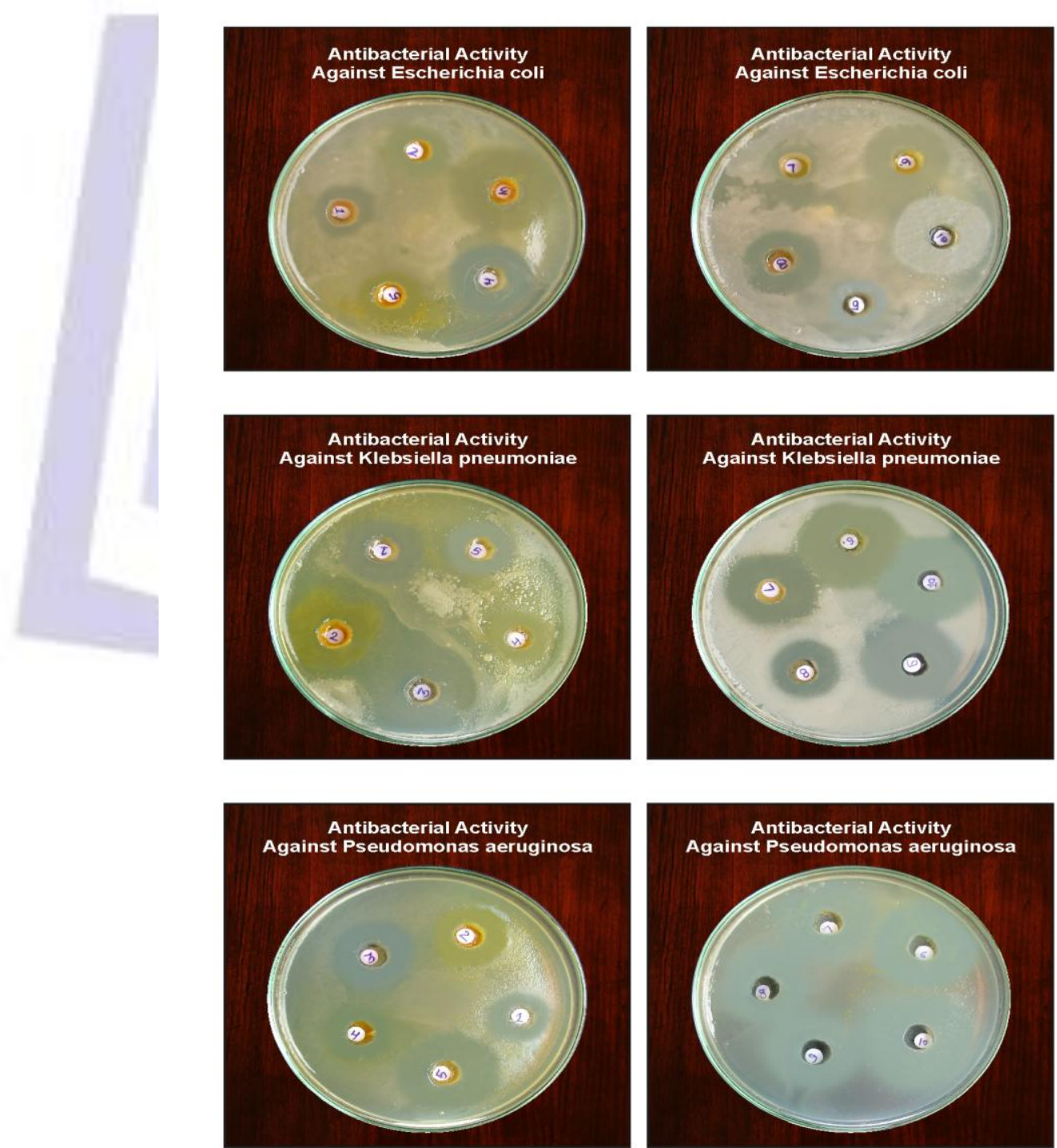

Figure a 

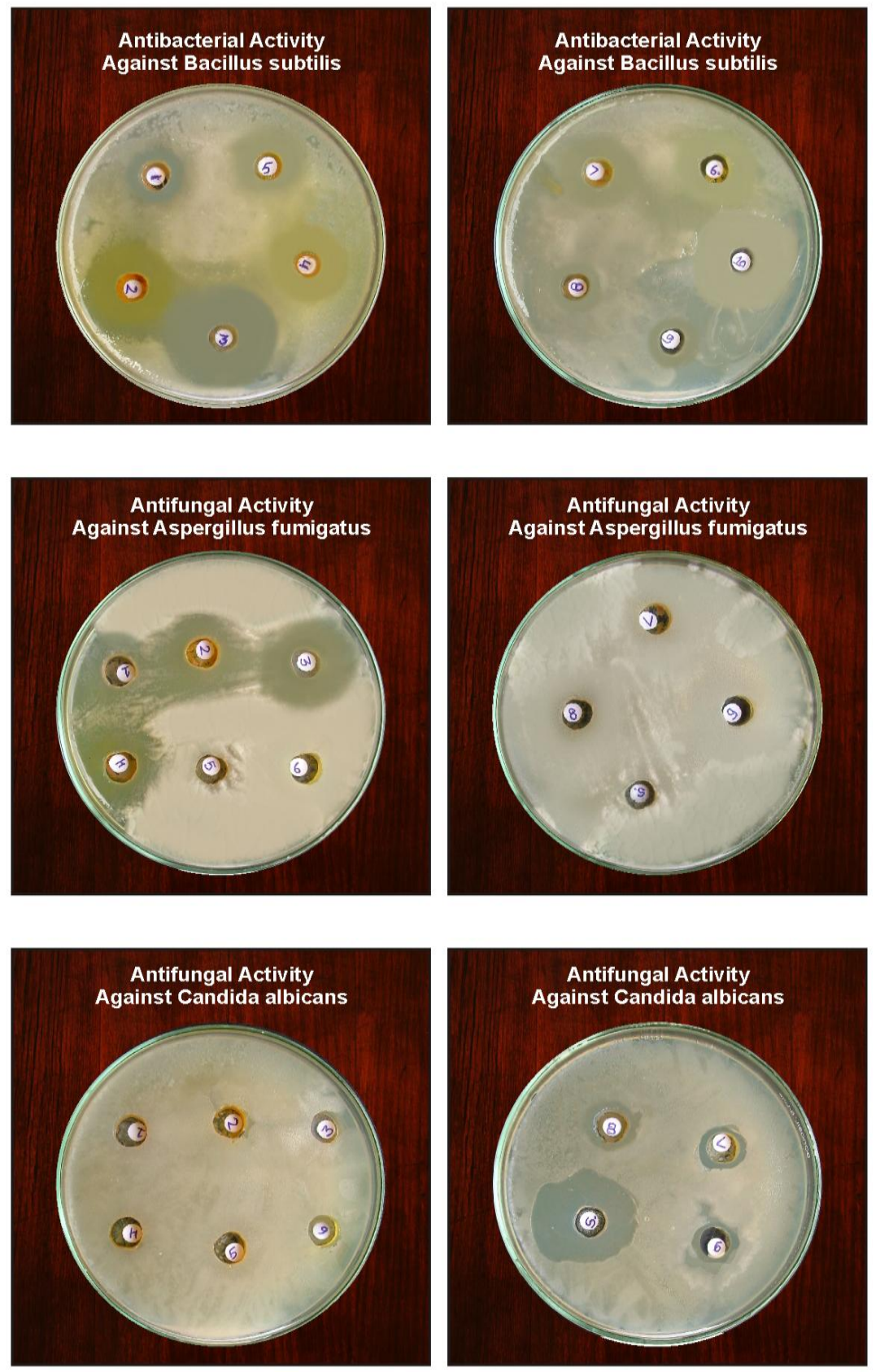

Figure $b$

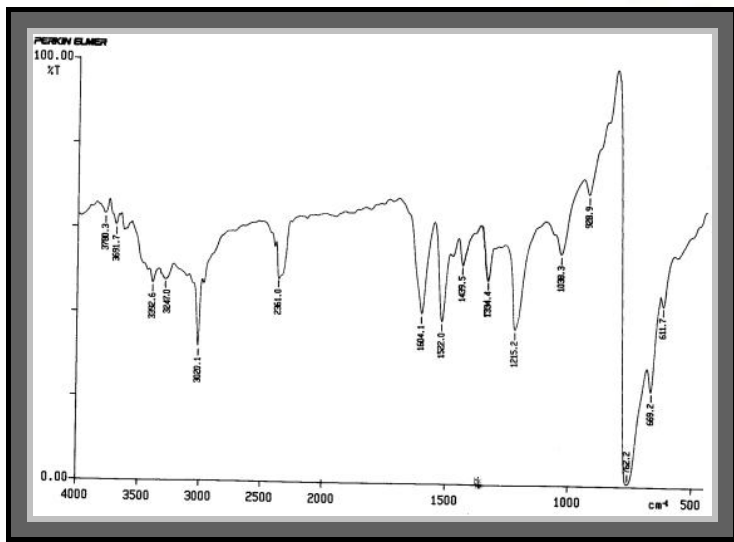

Figure1: FTIR Spectra of 2-amino-4-phenyl thiazole

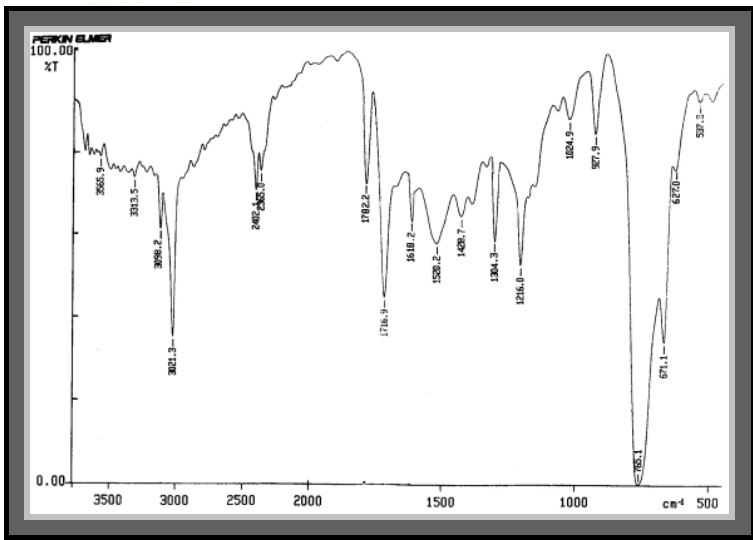

Figure2: FTIR Spectra of PTHPMI 


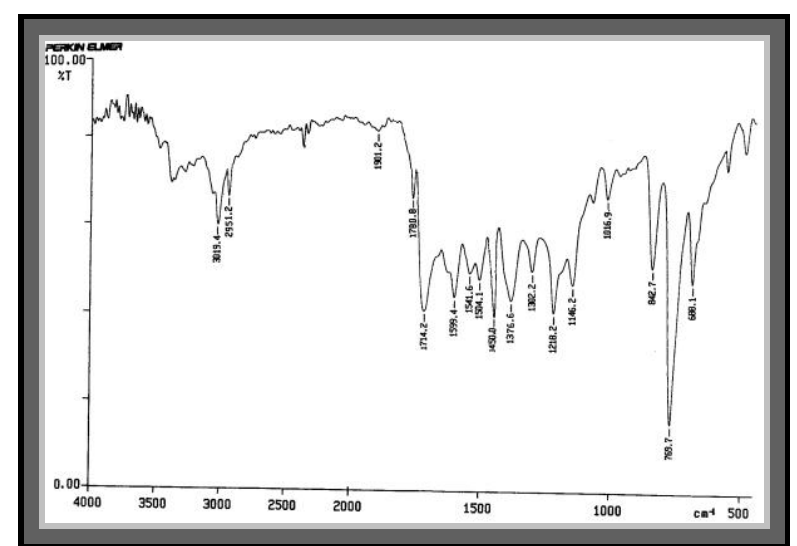

Figure 3: FTIR Spectra of HPAPMI

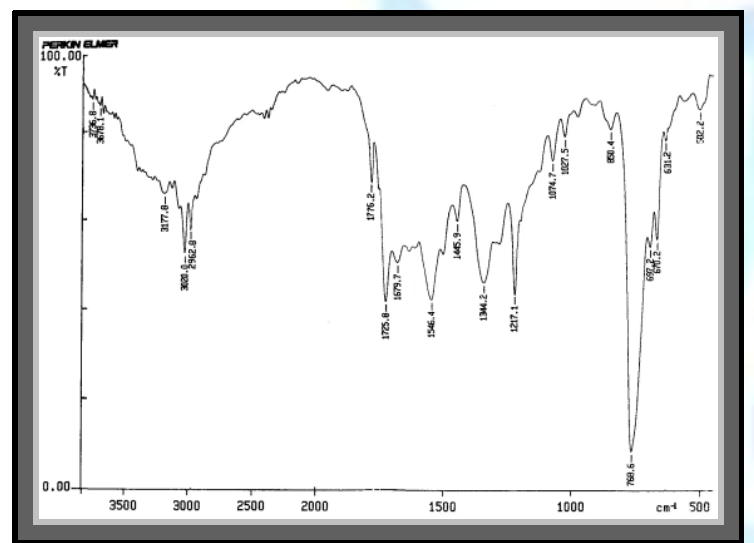

Figure 5: FTIR Spectra of HPTHPMI

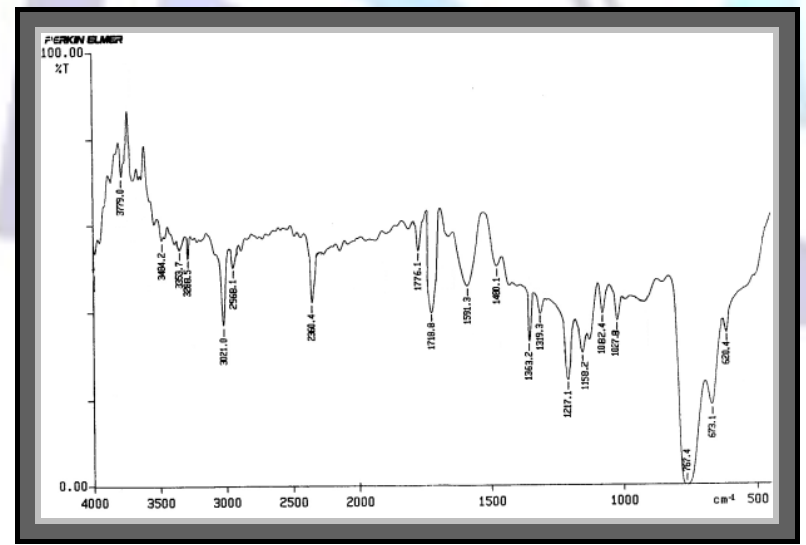

Figure7 : FTIR Spectra of PATHSPMI

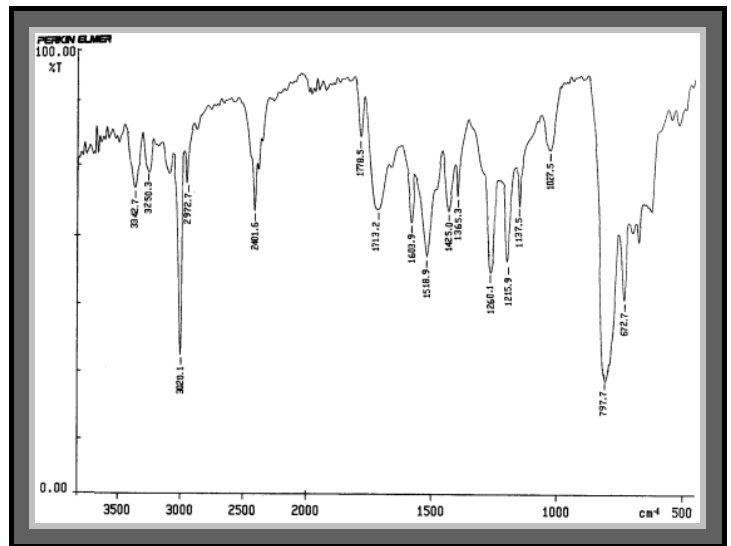

Figure 4: FTIR Spectra of HPSPM

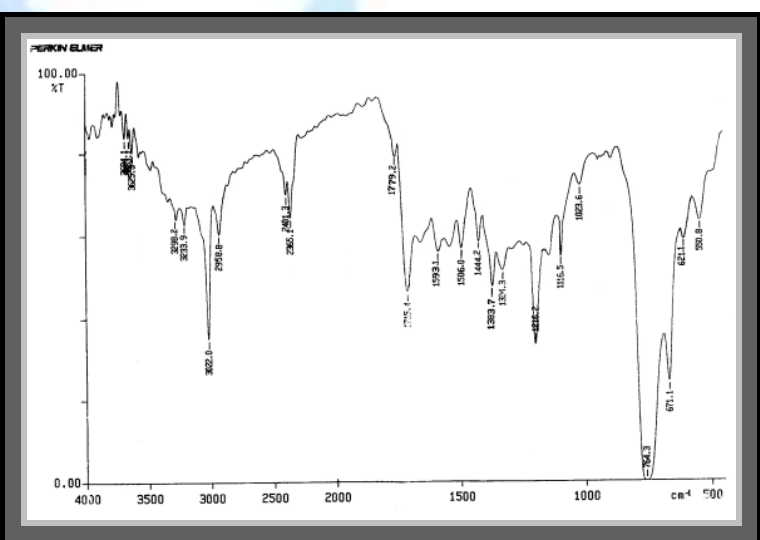

Figure 6 : FTIR Spectra of PTHSPMI

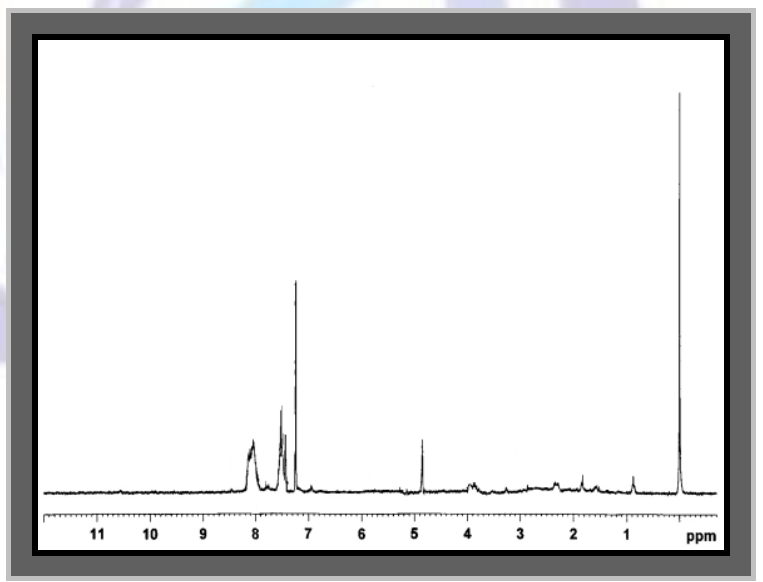

Figure 1.1: ${ }^{1} \mathrm{H}-\mathrm{NMR}$ Spectra of 2-amino-4-phenyl thiazol 


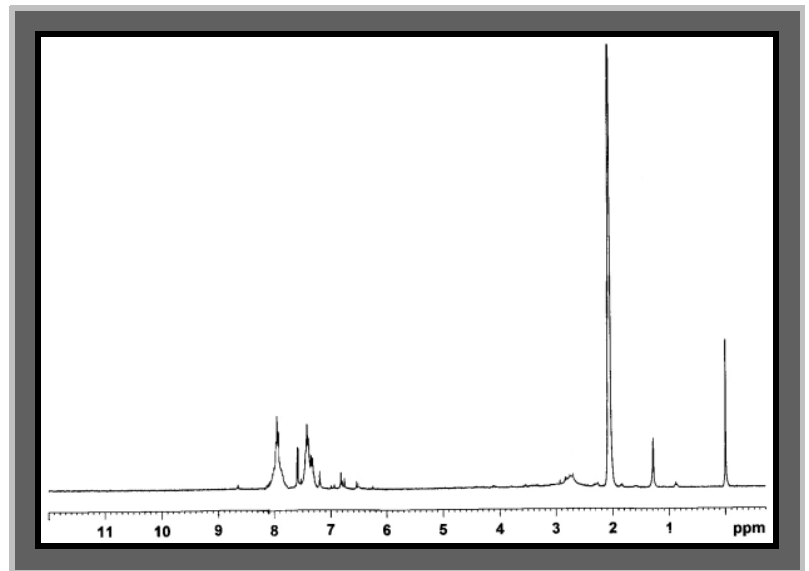

Figure 2.1: ${ }^{1} \mathrm{H}-\mathrm{NMR}$ Spectra of PTHPMI

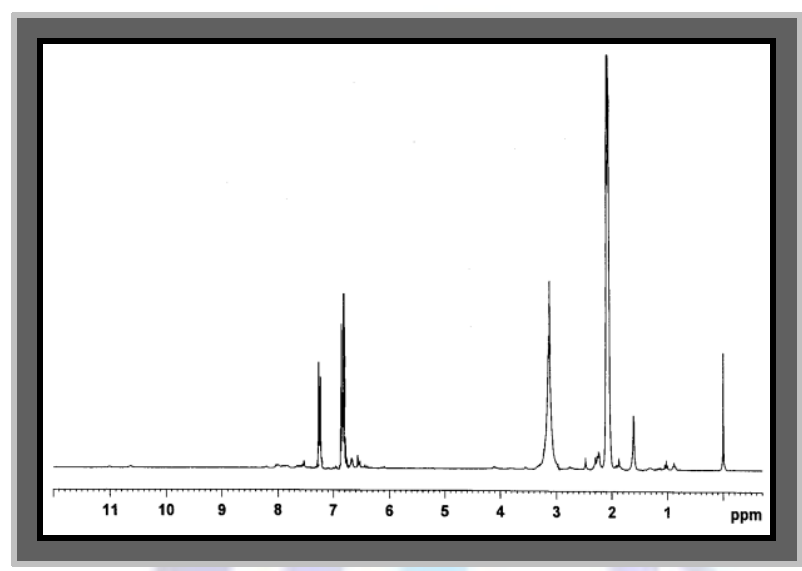

Figure 4.1: ${ }^{1} \mathrm{H}-\mathrm{NMR}$ Spectra of HPSPMI

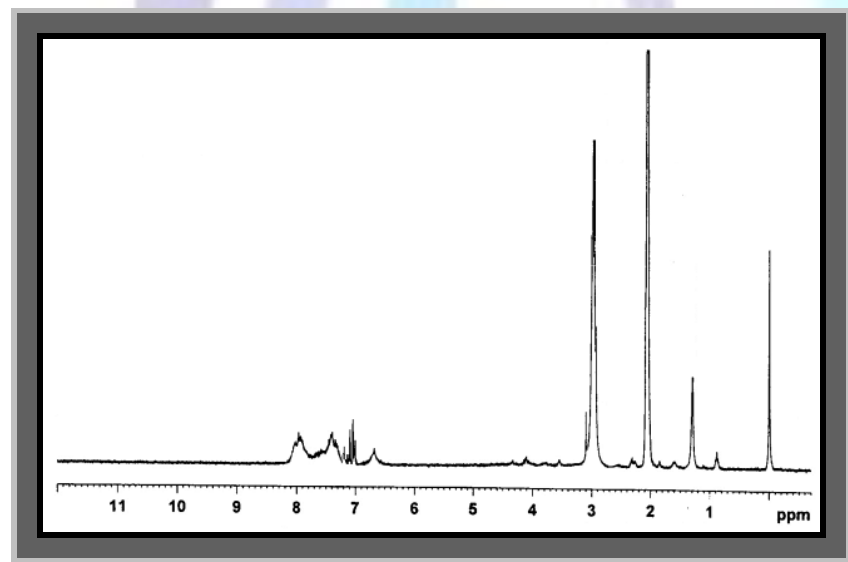

Figure 6.1: ${ }^{1} \mathrm{H}-\mathrm{NMR}$ Spectra of PTHSPMI

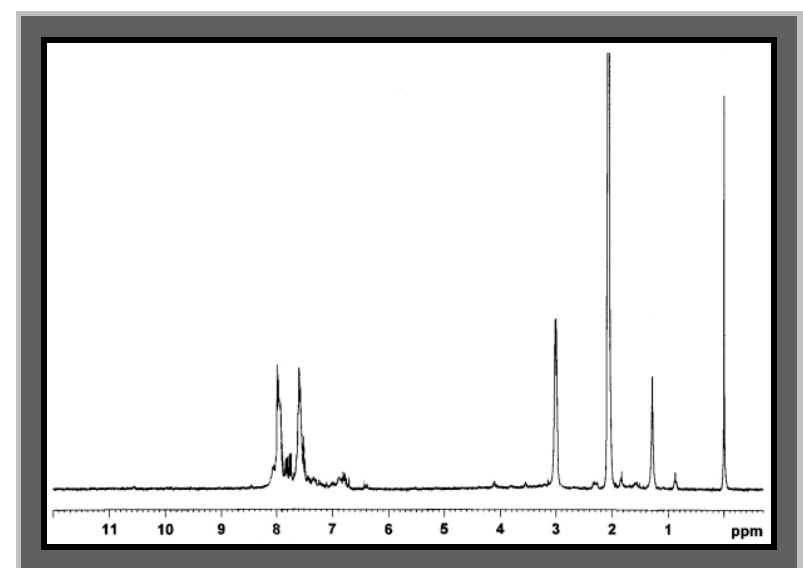

Figure3.1: ${ }^{1} \mathrm{H}-\mathrm{NMR}$ Spectra of HPAPMI

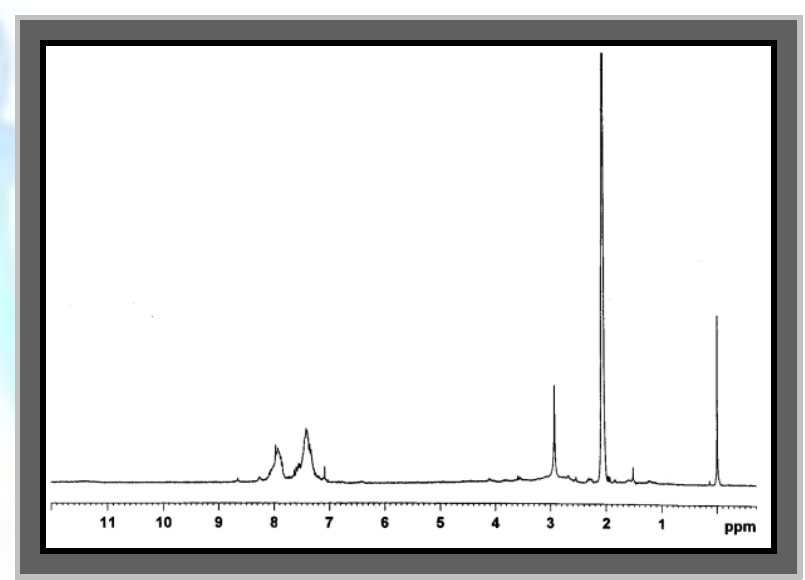

Figure 5.1: ${ }^{1} \mathrm{H}-\mathrm{NMR}$ Spectra of HPTHPMI

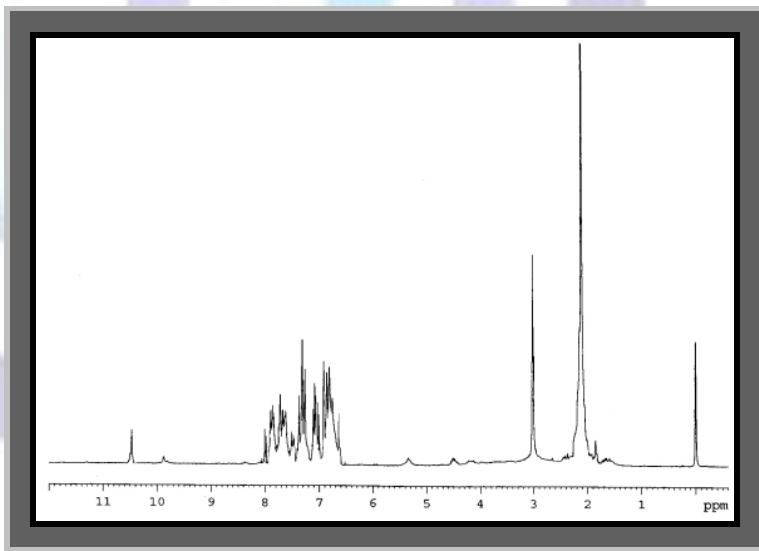

Figure6.1: ${ }^{1} \mathrm{H}$-NMR Spectra of PATHSPMI

\section{REFERANCES}

1. C.G. Gebelien and C.E. Carraher, 1994, Biotechnology and Bioactive Polymers, Springer, 225.

2. S.R.T. Prado, V. Cechinel-Filho, F. Campos-Buzzi, R. Correa, S. Cadena and M. Oliveria, 2004, Biological Evaluation of Some Selected Cyclic Imides: Mitochondrial Effects andin vitro Cytotoxicity, Zeitschrift für Naturforschung C, Vol. $59 \mathrm{c}, 663$.

3. R. Correa, P.W. Rosa, A. Bella Cruz, A.O.S. Savi, V. Cechinel Filho and R.J. Nunes, 1996, Synthesis and Antibacterial Activity of Citraconimides Pharmacy and Pharmacology Communications, 2(8), 353. 
4. J.J. Kabara, 1977, Aminimides: III antimicrobial effect of various hexadecyl and quaternary derivatives Journal of The American Oil Chemists' Society, 54(5), 202.

5. Orzesko, R. Gralewska, B.J. Starosciak and Z. Kazimierczuk, 2000, Synthesis and antimicrobial activity of new adamantane derivatives, Acta Biochimica Polonica, 47(1), 87.

6. L. Li, Z. Ke, G. Yan and J. Wu, 2008, Polyimide films with antibacterial surfaces from surface-initiated atom-transfer radical polymerization, Polymer International, Vol. 57(11), 1275.

7. S. Watanabe, Y. Lgarashi and K. Yagami, 1992, Antimicrobial activity of some $N$-(arylalkyl)maleimides, Pesticide Science, 34(2), 99.

8. Y. Lgarashi and S. Watanabe, 1992, Antimicrobial activities of 2-arylthio- $N$-alkylmaleimides, Journal of Industrial Microbiology \& Biotechnology, 9(2), 91.

9. P.S. Hadfield, L.A. Casey, R.H.B. Galt, B. Vilanova and M.I. Page, 2002, Imide and isatin derivatives as $y$-lactam mimics of B-lactam Antibiotics, ARKIVOC, Vol. (vi), 125.

10. F. Zentz, C. Hellio, A. Valla, D. Braise, G. Bermer and R. Labia, 2002, Antifouling activities of N-substituted imides: antimicrobial activities and inhibition of Mytilus edulis phenoloxidase, Marine Biotechnology (NY), Vol. 4(4), 431.

11. S. Watanabe, Y. Lgarashi, K. Yagami and R. Imai, 1991, Antimicrobial activity of some $N$ (fluorophenyl)maleimides Pesticide Science, 31(1), 45.

12. C. Umamaheswara Reddy, A. Arun, A. Amalraj and B.S. Reddy, 2007, Polymeric drug based on sulfanilamide: synthesis, antimicrobial and drug releasing studies, The Journal of Pharmacy and Pharmacology, 59(9), 1207.

13. T.V. Shehuka and A.S. Dimoglo, 1995, Structural characteristics of sulfanilamides with antimicrobial activity, Pharmaceutical Chemistry Journal, 29(10), 697.

14. D. Singh, M. Srivastava, A.K. Gyananchandran and P.D. Gokulan, 2010, Synthesis and Biological Evaluation of Some New Phenylthiazole Derivatives for their Antimicrobial Activities, Journal of Current Pharmaceutical Research, Vol. 4, 16.

15. S. Bondock, W. Fadaly and MA. Metwally, 2010, Synthesis and antimicrobial activity of some new thiazole, thiophene and pyrazole derivatives containing benzothiazole moiety, European Journal of Medicinal Chemistry, 45(9), 3692.

16. El-R. Kenawy, S.D. Worley and R. Broughton, 2007, The Chemistry and Applications of Antimicrobial Polymers: A State-of-the-Art Review, Biomacromolecules, 8(5),1359.

17. D. Singh, M. Srivastava, A.K. Gyananchandran and P.D. Gokulan, 2010, Synthesis and Biological Evaluation of Some New Phenylthiazole Derivatives for their Antimicrobial Activities Journal of Current Pharmaceutical Research, 4, 16.

18. O.A. Adegoke, A.O. Ogunleye, O.T. Lawal, O.S. Idowu and M.A. Adeniyi-Akee, 2010, Antimicrobial properties of 4Carboxyl-2, 6- Dinitrophenylazohydroxynaphthalenes African Journal of Microbiology Research, 4(22), 2444.

19. H. Özkan and Y. Yildirir, 2010, Synthesis of isomeric 2,3,5-trisubstituted perhydropyrrolo[3,4-d]-isoxazole-4,6-diones via 1,3-dipolar cycloaddition reactions Journal of Heterocyclic Chemistry, 47(4), 954.

20. H.M. Shukla, A.I. Shah, P.J. Shah and D.S. Raj, 2010, Co-ordination Polymers of Azo Group Containing Bis Ligand Rasayan Journal of Chemistry, 3(3), 525

21. B.L. Hiran, S. Bapna, D. Singh and J. Khuntwal, 2011, Free Radical Copolymerization of N-Substituted Maleimide Monomers Initiated using Azobisisobutyronitrile, International Journal of Chemistry and Chemical Engineering, 1(1), 1 